attendees from over 70 developing countries and some 500 renowned scientists including six Nobel laureates. This year it again attracted participants from more than ten countries. The college was divided into four parts and for each part the participants were largely different with less than $10 \%$ attending the whole two weeks. The small size of the college (40 at any one time) provided an excellent opportunity for the participants and lecturers to share their knowledge and experience.

Synchrotron radiation sources and their applications formed the subject of one of these parts (5-7 July). An additional interest among the participants was provided by exposure to the SESAME project, its status and opportunities. Pakistan is one of the founding members of SESAME. Herwig Schopper, President of the SESAME Council, formerly the Director General of CERN, gave the Abdus Salam lecture. He focused on the establishment of SESAME as an international project and stressed the need for a step change in science funding and infrastructure in the region. Economic development would only come from such bold action. Louise Johnson from Oxford, and Life Sciences director of Diamond, gave an overview on 'Synchrotron Radiation in the Life Sciences'. She concluded her talk with a quote from the originator of the Nathiagali Summer College, Abdus Salam, 'Science and technology are cyclical. They are a shared heritage of all mankind. East and west, north and south have all equally participated in their creation in the past, as we hope that they will in the future, the joint endeavor in sciences becoming one of the unifying forces among diverse peoples of this globe'. Zahid Hussain (ALS, Berkeley), Herman Winick (SSRL, Stanford) and Samar Hasnain (SRS, Daresbury) each gave several lectures and covered the sources, beamline design and science applications in physical, environmental and biological disciplines.

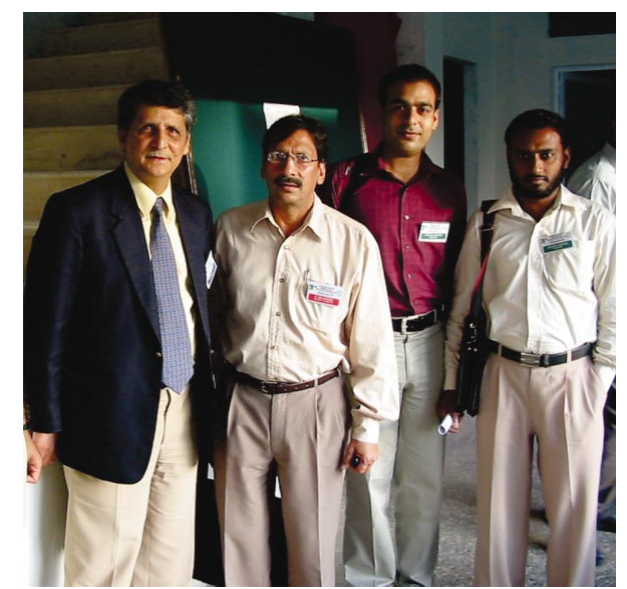

Samar Hasnain standing with Professor Aslam Baig, Science Chair of the Synchrotron Radiation and Laser Physics Summer College, with a couple of his research students. Professor Baig is the chairman of the Physics Department at Quaid-e-Azam University and has been appointed as the Scientific Director of SESAME.

\section{The Queen honours John Pendry}

John Pendry was honoured in the recent Queen's birthday honours list with a knighthood for his services to science, so it is now Sir John Pendry who has turned 60. Sir John is well known to the synchrotron community through his theoretical formulism of EXAFS and XANES [Lee \& Pendry (1975), Phys. Rev. B, 11, 2795-2811] which, together with the work of Ashley \& Doniach [Phys. Rev B, (1975), 11,
1279-1288], has formed the basis of most of the rigorous analysis packages (EXCURVE, GNXS, FEFF etc.) used by thousands of EXAFS and XANES practitioners around the synchrotron world. At the time of the first international meeting on EXAFS, held at Daresbury on 28-29 March 1981, he was the head of the theory group at Daresbury laboratory and gave a talk entitled 'The theoretical basis of EXAFS and edge structure' [see EXAFS for Inorganic Systems, (1981), Daresbury Report DL/SCI/R17, pp. 5-12, edited by C. D. Garner and S. S. Hasnain]. He had formulated his theoretical formulism based on his previous work on the theoretical basis of a surface technique, LEED. His book, entitled Low-Energy Electron Diffraction (Academic Press, 1974), has remained an essential reading for surface scientists over the last three decades.

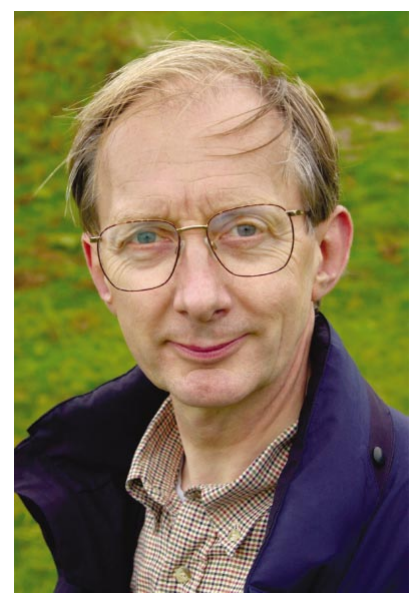

John Pendry.

Sir John began his career at the Cavendish Laboratory, Cambridge, followed by six years at the Daresbury Laboratory, where he headed the theoretical group from 1975 to 1981 . He moved to the Blackett Laboratory, Imperial College, London, in late 1981. He was elected a Fellow of the Royal Society and a Fellow of the Institute of Physics in 1984. During his time at Imperial College he held all of the senior scientific appointments possible at the college: Dean of the Royal College of Science from 1993 to 1996; Head of the Department of Physics from 1998 to 2001 and the first Principal of the Faculty of Physical Sciences from 2001 to 2002.

In 2000, Sir John published a series of papers building on forgotten work by Russian physicist Victor Veselago from 1968, which laid the theoretical ground for the development of special left-handed or 'metamaterials' that could be used to form perfect lenses [see, for example, Pendry (2003), Nature (London), 423, 22-23]. Currently, Sir John is working on new optical materials developed jointly with colleagues at the Marconi company, which may lead to DVD discs with much higher information density, and to higher-resolution optical lithography for computer chips. Speaking in March this year he was open-minded about the eventual applications for metamaterials, 'I believe that the really valuable applications have yet to be dreamt of. Think back to when the first lasers were made, the reaction was that they were just incredible, but what the hell would we do with them?'. Sir John, a theorist, has proved consistently insightful when asked to describe the relevance of physics to the world. Challenged in 1997 to give the college a glimpse of where he saw research in his discipline heading, he described physics as a practical enabling discipline 'showing how to do things thought impossible, helping others refine their approach.' 'Physics is to the rest of science what machine tools are to engineering', he wrote in a recent essay. 